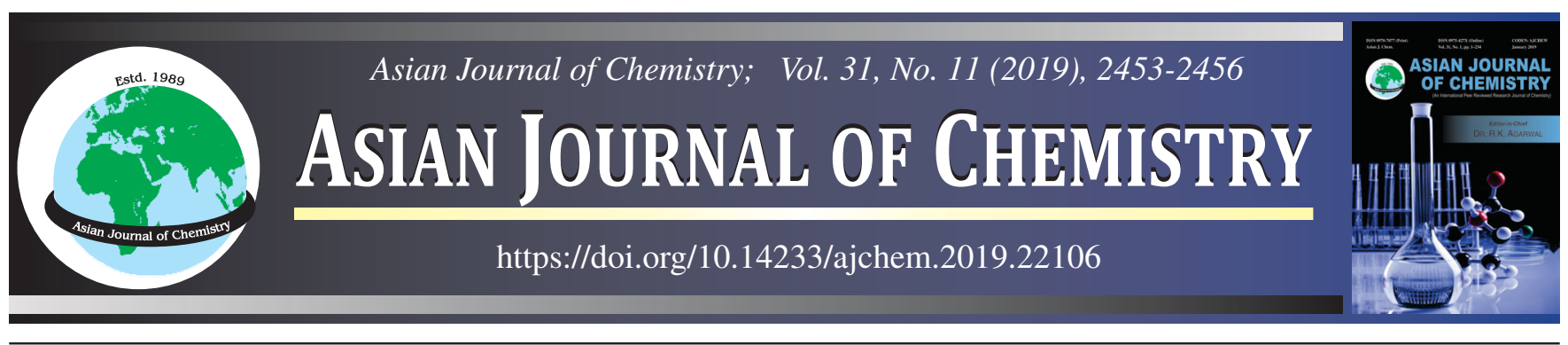

\title{
Synthesis and Molecular Docking Studies of Coumarinyl \\ Thiazole as Cell Division Protein Kinase 2 Inhibitor
}

\section{J. BRINDHA ${ }^{1,2, ®}$ and T.F. Abbs Fen RejI,*}

${ }^{1}$ Manonmaniam Sundaranar University, Tirunelveli-627012, India

${ }^{2}$ Department of Chemistry, Nesamony Memorial Christian College, Marthandam-629165, India

*Corresponding author: E-mail: abbsfen@gmail.com

Received: 30 March 2019;

Accepted: 3 May 2019;

Published online: 28 September 2019;

AJC-19568

A series of 2-alkylamino-4-(3-coumarinyl)thiazoles were synthesized, characterized and evaluated their anticancer activity through molecular docking studies. Cell division protein kinase 2 (PDB code: 1KE9) is selected as a target and the compounds which obeys Lipinski rule of five is selected as a ligand. Molecular docking study is carried out using AutoDock Vina in PyRx virtual screening tool. This study revealed that all the compounds are active against the molecular target and compounds $\mathbf{5} \mathbf{a}$ and $\mathbf{5} \mathbf{c}$ have the highest docking score.

1

Keywords: Thiazole derivatives, Molecular docking, Protein kinase 2, Lipinski rule, Anticancer activity.

\section{INTRODUCTION}

Organic and medicinal chemists have great interest in coumarins and their derivatives because of their extensive medicinal applications such as antitubercular [1,2], antiviral [3], anti-inflammatory [4], cholinesterase inhibitors [5,6] and anticancer activities [7-10]. 3-Heteroarylamino-2,4'-coumarinyl2,3-dihydrobenzofurans exhibit both binding activity and DNA cleavage against $E$. coli, particularly DNA binding was prominently observed with all the compounds making them fine candidates for interactive studies with DNA [11]. Halogenated coumarin analogues have the potential to be used to inhibit and control malaria by controlling the vector A. arabiensis [12]. The antimicrobial and analgesic activity data shows that coumarinyl thiazole azo dyes contain electron donating substituent developed effective results and therefore might act as a lead molecule to become acquire more clinically useful [13]. The cytotoxic study and antimicrobial activity of 2,4-disubstituted [1,3]thiazoles revealed that thiazoles display good cytotoxicity and antimicrobial activity [14]. The Schiff bases of aminothiazolylchlorocoumarins have shown attractive biological activity based on the presence of certain functional groups [15]. These evidences confirm coumarin ring have significant activity against bacteria and fungi. The introduction of thiazole ring in heterocyclic compounds possessing incredible activity against bacteria and introduction of 2-amino-thiazole derivatives are also reported to exhibit considerable biological activity [16].

The wide range of biological activities of coumarin derivatives has further inspired more research towards coumarin derivatives, which allows designing a large number of structurally diverse derivatives. Coumarin structure has been considered as a pharmacophore to create new anticancer agents attributed to the above constructive profiles. Novel drug discovery and development process is generally time-consuming, risky and costly [17]. Consequently, various approaches have been developed to shrink the research cycle and reduce the outlay and risk of failure for drug discovery. One of the most effective methods for reaching these goals is computer aided drug design (CADD) [18]. For searching new anticancer agents, coumarin-containing derivatives have been synthesized and screened for their anticancer activity using AutoDock Vina in PyRx virtual screening tool.

\section{EXPERIMENTAL}

Synthesis of 3-bromoacetylcoumarin (3): 3-Acetylcoumarin was synthesized by Knoevenagel condensation. A mixture of salicylaldehyde $(0.01 \mathrm{mmol})$, ethylacetoacetate $(0.01 \mathrm{mmol})$, piperidine (4 drops), glacial acetic acid ( 2 drops) and ethanol $(20 \mathrm{~mL})$ was refluxed for $5 \mathrm{~h}$ and the reaction mixture was poured into cold-water, filtered, washed and dried to yield 3-

This is an open access journal, and articles are distributed under the terms of the Attribution 4.0 International (CC BY 4.0) License. This license lets others distribute, remix, tweak, and build upon your work, even commercially, as long as they credit the author for the original creation. You must give appropriate credit, provide a link to the license, and indicate if changes were made. 
acetylcoumarin (3). It was then brominated using bromine in acetic acid $(0.01 \mathrm{mmol})$. The crystals of 3-bromoacetyl coumarin (4) formed were collected, washed with minimum quantity of glacial acetic acid, dried and recrystallized [19].

General procedure for the synthesis of 2-alkylamino4-(3-coumarinyl)thiazoles (5a-d): A solution of 3-bromoacetylcoumarin $(0.005 \mathrm{~mol})$ in hot ethanol was treated with alkylthiourea $(0.01 \mathrm{~mol})$, a mild exothermic reaction giving a clear solution that soon deposited as crystals. The crystals were separated, washed with ethanol and boiled with water containing sodium acetate, which yielded 2-alkylamino-4-(3-coumarinyl)thiazoles and the product obtained was recrystallized with ethanol.

2-Ethylamino-4-(3-coumarinyl)thiazole (5a): Orange solid, yield: $70 \%$; m.w.: 272 g/mol; IR (KBr, $\left.v_{\max }, \mathrm{cm}^{-1}\right): 3130$ (Ar-C-H), 1729 (C=O of lactone), 1555, 1488 (Ar C=C), 1450, 1401 (alkyl C-H), 1302 (C-N), 757 (C-S); ${ }^{1} \mathrm{H}$ NMR (400 MHz, DMSO- $d_{6}$ ) $\delta: 8.893$ (s, $1 \mathrm{H}, \mathrm{H}_{1}$-coumarin), 8.012-8.082 (d, $1 \mathrm{H}$, $\mathrm{H}_{2}$-coumarin), 7.738-7.849 (m, $2 \mathrm{H}, \mathrm{H}_{3} \& \mathrm{H}_{5}$-coumarin), 7.8687.991 (t, 1H, $\mathrm{H}_{4}$-coumarin), 8.974 (s, 2H, thiazole \& $\left.-\mathrm{NH}\right), 3.411$ 3.463 (q, 2H, $\left.-\mathrm{CH}_{2}\right), 1.034-1.226\left(\mathrm{t}, 3 \mathrm{H},-\mathrm{CH}_{3}\right) ;{ }^{13} \mathrm{C} \mathrm{NMR}(400$ $\left.\mathrm{MHz} \mathrm{CDCl}_{3}\right)$ : 149.74, 135.45, 135.33, 130.76, 130.64, 125.59, 125.52, 122.52, 117.13, 50.24, 35.77; MS (ESI-MS) m/z: 273 $\left(\mathrm{MH}^{+}\right)$.

2-Propylamino-4-(3-coumarinyl)thiazole (5b): Orange solid, yield: $62 \%$; m.w.: 286 g/mol; IR $\left(\mathrm{KBr}, \mathrm{v}_{\max }, \mathrm{cm}^{-1}\right): 3251$ (-NH-), 3043 (Ar- C-H), 1730 (C=O of lactone), 1487 (Ar C=C), 1451, 1370 (alkyl C-H), 1279 (C-N), 1217 (C-O), 757 (C-S); ${ }^{1} \mathrm{H}$ NMR (400 MHz, DMSO- $\left.d_{6}\right) \delta: 8.740$ (s, $1 \mathrm{H}, \mathrm{H}_{1}$-coumarin), 7.994-8.013 (d, 1H, $\mathrm{H}_{2}$-coumarin), 7.393-7.546 (m, 2H, $\mathrm{H}_{3}$ \& $\mathrm{H}_{5}$-coumarin), 7.740-7.838 (t, $1 \mathrm{H}, \mathrm{H}_{4}$-coumarin), 8.956 (s, $1 \mathrm{H}$, thiazole), 8.832 (s, $1 \mathrm{H},-\mathrm{NH}), 3.586-3.618\left(\mathrm{~m}, 2 \mathrm{H},-\mathrm{CH}_{2}\right), 1.152-$ $1.228\left(\mathrm{~m}, 2 \mathrm{H},-\mathrm{CH}_{2}\right), 1.036-1.071\left(\mathrm{t}, 3 \mathrm{H},-\mathrm{CH}_{3}\right)$.

2-Isopropylamino-4-(3-coumarinyl)thiazole (5c): Orange brown solid, yield: $68 \%$; m.w.: $286 \mathrm{~g} / \mathrm{mol}$; IR (KBr, $\left.v_{\max }, \mathrm{cm}^{-1}\right)$ : 3042 (Ar-C-H), 2957 (alkyl C-H), 1730 (C=O of lactone), 1554 (Ar C=C), 1450, 1368 (alkyl C-H), 1302 (C-N), 1249 (C-O), 757 (C-S); ${ }^{1} \mathrm{H}$ NMR (400 MHz, DMSO- $\left.d_{6}\right) \delta: 8.745$ (s, $1 \mathrm{H}, \mathrm{H}_{1^{-}}$ coumarin), 8.035-8.095 (d, 1H, $\mathrm{H}_{2}$-coumarin), 7.400-7.535 (m, $2 \mathrm{H}, \mathrm{H}_{3} \& \mathrm{H}_{5}$-coumarin), 7.745-7.831 (t, $1 \mathrm{H}, \mathrm{H}_{4}$-coumarin), 8.965 (s, 1H, thiazole), $3.592-3.426(\mathrm{~m}, 1 \mathrm{H},-\mathrm{CH}), 0.980-1.093(\mathrm{~d}$, $\left.6 \mathrm{H},-\mathrm{CH}_{3}\right), 8.832(\mathrm{~s}, 1 \mathrm{H},-\mathrm{NH})$.

2-Butylamino-4-(3-coumarinyl)thiazole (5d): Orange brown solid, yield: $74 \%$; m.w.: $300 \mathrm{~g} / \mathrm{mol}$; IR $\left(\mathrm{KBr}, \mathrm{v}_{\max }, \mathrm{cm}^{-1}\right)$ : 3130 (Ar-C-H), 1730 (C=O of lactone), 1554, 1487 ( $\mathrm{Ar} \mathrm{C}=\mathrm{C}$ ), 1449, 1369 (alkyl C-H), 1302 (C-N), 1181 (C-O), 757 (C-S); ${ }^{1} \mathrm{H}$ NMR (400 MHz, DMSO- $d_{6}$ ) $\delta: 8.692$ (s, $1 \mathrm{H}, \mathrm{H}_{1}$-coumarin), 7.970-8.009 (d, 1H, $\mathrm{H}_{2}$-coumarin), 7.408-7.507 (m, 2H, $\mathrm{H}_{3}$ \& $\mathrm{H}_{5}$-coumarin), 7.738-7.807 (t, $1 \mathrm{H}, \mathrm{H}_{4}$-coumarin), 8.830 (s, $1 \mathrm{H}$, thiazole), 3.962-4.009 (q, 2H, $\left.-\mathrm{CH}_{2}\right), 1.556-1.630\left(\mathrm{~m}, 2 \mathrm{H},-\mathrm{CH}_{2}\right)$, 1.110-1.234 (m, 2H, $\left.-\mathrm{CH}_{2}\right), 1.033-1.068$ (t, 3H, $\left.-\mathrm{CH}_{3}\right) ; 8.738$ (s, 1H, -NH).

Molecular docking studies: The structures of 2-alkylamino-4-(3-coumarinyl)thiazoles were modeled, optimized and energy minimized using Gaussian 09 software. Ligand selection depends on the compounds which are obeying Lipinski rule of five. The optimized compounds were used to perform molecular docking. The 3D structure of the molecular target was obtained from Protein Data Bank (PDB code: 1KE9). The docking study was performed using AutoDock Vina in PyRx and Pymol for visualization.

\section{RESULTS AND DISCUSSION}

The synthesis of 2-alkylamino-4-(3-coumarinyl)thiazoles was carried out as outlined in Scheme-I. The starting compound of 3-acetylcoumarin was prepared by refluxing a mixture of ethylacetoacetate and salicylaldehyde in ethanol in the presence of a catalytic amount of piperidine, acetic acid and brominated using bromine in acetic acid. The $N$-alkylthiourea was prepared by heating the mixture of alkylamine, ammonium thiocyanate, hydrochloric acid and water. 2-Alkylamino-4-(3-coumarinyl)thiazoles were synthesized by reaction of 3-bromoacetylcoumarin with $N$-alkylthioureas in hot ethanol and crystals obtained were boiled with water containing sodium acetate. The yields of the final compounds (5a-d) ranged from 62 to $74 \%$ after recrystallization with ethanol. The purity of compounds were checked throughout by thin layer chromatography (TLC).

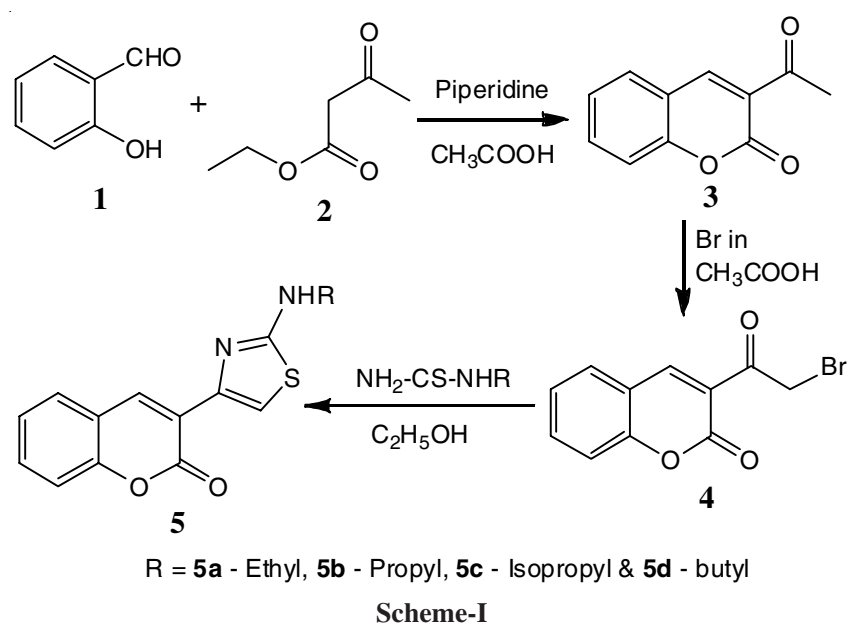

The FT-IR, ${ }^{1} \mathrm{H}$ NMR, ${ }^{13} \mathrm{C}$ NMR and ESI-MS were used to characterize the synthesized compounds. The spectral data obtained were in good agreement with the proposed structures. The FT-IR spectrum of the synthesized compounds showed the presence of strong characteristic band at 3130-3042 $\mathrm{cm}^{-1}$ corresponding to the aromatic $\mathrm{C}-\mathrm{H}$ stretching band. The band at $1451-1368 \mathrm{~cm}^{-1}$ represents the alkyl $\mathrm{C}-\mathrm{H}$ bending band. The other prominent absorption bands observed in the IR spectrum were $1730(\mathrm{C}=\mathrm{O}), 1555(\mathrm{Ar} \mathrm{C}=\mathrm{C})$ and $1370 \mathrm{~cm}^{-1}(\mathrm{C}-\mathrm{N})$, respectively.

The ${ }^{1} \mathrm{H}$ NMR spectra recorded for these compounds clearly supported the proposed structures. Thiazole protons of the synthesized compounds were observed at 8.974, 8.956, 8.965 and $8.830 \mathrm{ppm}$ respectively. All the other additional peaks observed were in agreement with the protons on the corresponding substituents and coumarin ring. The ${ }^{13} \mathrm{C}$ NMR spectra of the compounds confirmed the number of carbon atoms present in the synthesized compounds. The ESI-MS spectrometric data value is also in full accordance with the proposed structures.

The molecular docking studies of 2-alkylamino-4-(3coumarinyl)thiazoles were carried to identify binding affinity and interactions between the ligand and the active site of target. 
2-Alkylamino-4-(3-coumarinyl)thiazoles which obey Lipinski rule of five (Table-1) were selected for the docking studies. Lipinski rule of five is used to evaluate drug likeness or determine if a chemical compound has properties of certain biological activity. All the compounds obey the Lipinski rule of five hence, the molecules are docked into the active site of cell division protein kinase 2 (PDB code: 1KE9) by AutoDock Vina in PyRx virtual screening tool. The docking score of compounds are summarized in Table-2. The docking scores indicated that synthesized compounds are more active against 1KE9. Molecular docking study revealed that compounds $\mathbf{5 a}$ and $\mathbf{5 c}$ are most promising compounds which are explained by lowest binding energy and interactions with the active site residues of 1KE9. However, on comparing with the result of all the compounds 5a and 5c have highest docking score (-6.9). The 2D pose of all the ligands and the active site 1KE9 is shown in Fig. 1. The intermolecular hydrogen bond in the molecular target is shown as yellow dotted lines in Fig. 1. The binding mode of compounds in the active site of $1 \mathrm{KE} 9$ showed backbone hydrogen bonding of NH group with residues ASP 86, PRO 253 and SER 181 and C-O group in coumarin ring with residues ALA 277 and ARG 297 and also residue ASP 86 is bounded with both nitrogen

TABLE-1

LIPINSKI RULE OF 2-ALKYLAMINO-4-(3-COUMARINYL)THIAZOLES

\begin{tabular}{cccccc}
\hline Compound & $\begin{array}{c}\text { Molecular weight } \\
<500 \text { Dalton }\end{array}$ & HB donar $<5$ & HB acceptor $<10$ & $\log$ P $<5$ & $\begin{array}{c}\text { Molecular refractivity } \\
40-130\end{array}$ \\
\hline $\mathbf{5 a}$ & 272 & 1 & 4 & 3.03 & 76.22 \\
$\mathbf{5 b}$ & 286 & 1 & 4 & 3.42 & 80.84 \\
$\mathbf{5 c}$ & 286 & 1 & 4 & 3.42 & 80.82 \\
$\mathbf{5 d}$ & 300 & 1 & 4 & 3.81 & 85.45 \\
\hline
\end{tabular}

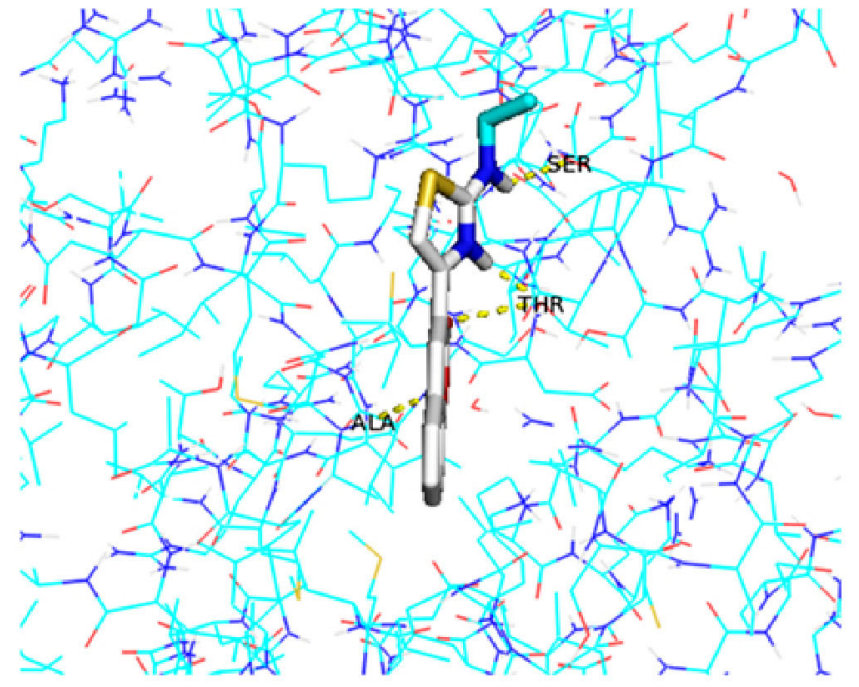

$5 a$

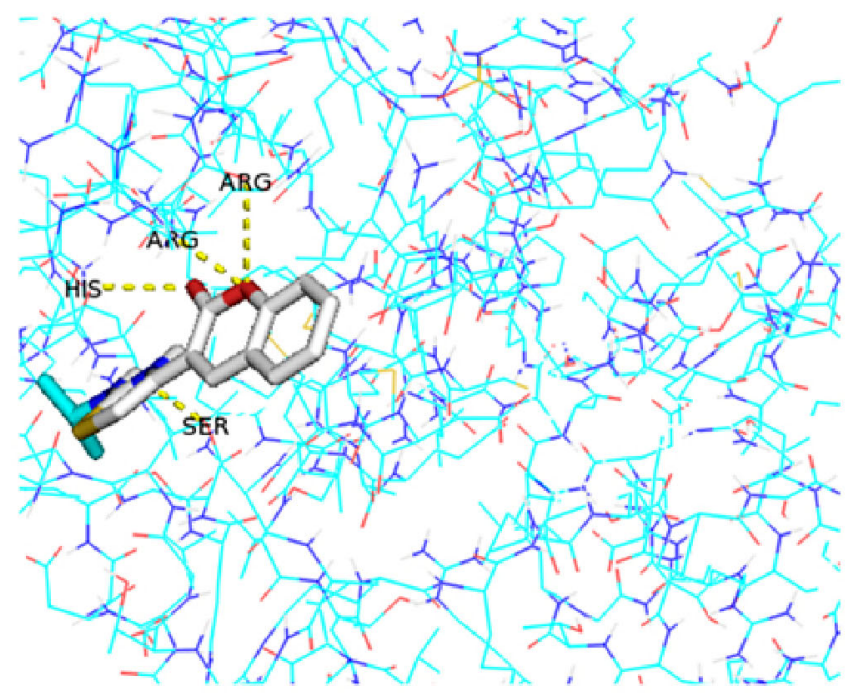

$5 c$

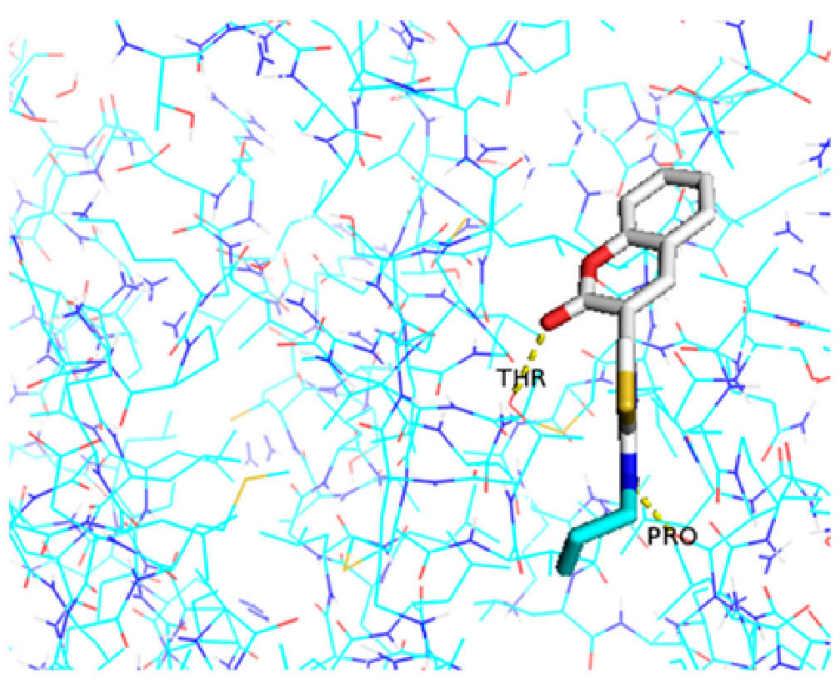

$5 b$

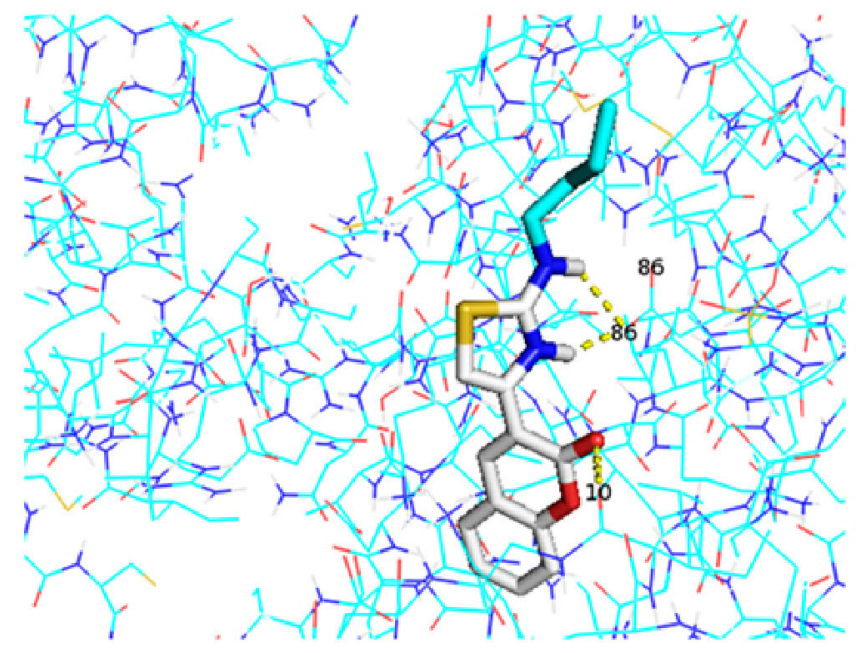

$5 d$

Fig. 1. Docking image of 2-alkylamino-4-(3-coumarinyl)thiazoles 


\begin{tabular}{ccc}
\hline & \multicolumn{2}{c}{ TABLE 2 } \\
& $\begin{array}{c}\text { DOCKING SCORE OF 2-ALKYLAMINO- } \\
\text { 4-(3-COUMARINYL)THIAZOLES }\end{array}$ \\
\hline Compound & $\begin{array}{c}\text { Docking score } \\
\left(\mathrm{KJ} \mathrm{mol}^{-1}\right)\end{array}$ & \multicolumn{1}{c}{ H-Bond } \\
\hline $\mathbf{5 a}$ & -6.9 & SER 181, THR 182, ALA 277 \\
$\mathbf{5 b}$ & -6.5 & THR 198, PRO 253 \\
$\mathbf{5 c}$ & -6.9 & SER 94, HIS 295, ARG 297 \\
$\mathbf{5 d}$ & -6.6 & ILE 10, ASP 86 \\
\hline
\end{tabular}

in thiazole ring and $\mathrm{NH}$ group and side chain hydrogen bonding of carbonyl group in coumarin with residues THR 198, HIS 295 and ILE 10. The residue THR 182 is bounded with both nitrogen in thiazole ring and carbonyl group in coumarin ring.

\section{Conclusion}

In summary, 2-alkylamino-4-(3-coumarinyl)thiazoles were designed, synthesized and their structures were characterized by FT-IR, ${ }^{1} \mathrm{H}$ NMR, ${ }^{13} \mathrm{C}$ NMR and ESI-MS. Furthermore, 2-alkylamino-4-(3-coumarinyl)thiazoles were docked towards the active site of cell division protein kinase 2 (PDB code: 1KE9) using PyRx virtual screening tool. The results showed that all the tested compounds have anticancer activity. Among the tested compounds, 5a and 5c showed highest docking score and four hydrogen bond interactions with 1KE9. This revealed that coumarin derivatives discovered in this study may provide valuable information in the field of drug design and cancer therapy.

\section{CONFLICT OF INTEREST}

The authors declare that there is no conflict of interests regarding the publication of this article.

\section{REFERENCES}

1. A. Stefanachi, F. Leonetti, L. Pisani, M. Catto and A. Carotti, Molecules, 23, 250 (2018);

https://doi.org/10.3390/molecules23020250.

2. R.S. Keri, B.S. Sasidhar, B.M. Nagaraja and M. Amelia-Santos, Eur. J. Med. Chem., 100, 257 (2015);

https://doi.org/10.1016/j.ejmech.2015.06.017.
3. M.Z. Hassan, H. Osman, M.A. Ali and M.J. Ahsan, Eur. J. Med. Chem., 123, 236 (2016); https://doi.org/10.1016/j.ejmech.2016.07.056.

4. H.M. Revankar, S.N.A. Bukhari, G.B. Kumar and H.-L. Qin, Bioorg. Chem., 71, 146 (2017); https://doi.org/10.1016/j.bioorg.2017.02.001.

5. L.G. de Souza, M.N. Renno and J.D. Figueroa-Villar, Chem. Biol. Interact., 254, 11 (2016); https://doi.org/10.1016/j.cbi.2016.05.001.

6. P. Anand, B. Singh and N. Singh, Bioorg. Med. Chem., 20, 1175 (2012); https://doi.org/10.1016/j.bmc.2011.12.042.

7. K. Nepali, S. Sharma, M. Sharma, P.M.S. Bedi and K.L. Dhar, Eur. J. Med. Chem., 77, 422 (2014); https://doi.org/10.1016/j.ejmech.2014.03.018.

8. A. Thakur, R. Singla and V. Jaitak, Eur. J. Med. Chem., 101, 476 (2015); https://doi.org/10.1016/j.ejmech.2015.07.010.

9. S. Emami and S. Dadashpour, Eur. J. Med. Chem., 102, 611 (2015); https://doi.org/10.1016/j.ejmech.2015.08.033.

10. D.K. Mahapatra, S.K. Bharti an V. Asati, Eur. J. Med. Chem., 98, 69 (2015); https://doi.org/10.1016/j.ejmech.2015.05.004.

11. A. Rescifina, C. Zagni, M.G. Varrica, V. Pistarà and A. Corsaro, Eur. J. Med. Chem., 74, 95 (2014); https://doi.org/10.1016/j.ejmech.2013.11.029.

12. V.K. Narayanaswamy, R.M. Gleiser, K. Kasumbwe, B.E. Aldhubiab, M.V. Attimarad and B. Odhav, Sci. World J., 2014, Article ID 189824, (2014); https://doi.org/10.1155/2014/189824.

13. M.R. Yazdanbakhsh, A. Mohammadi and M. Abbasnia, Spectrochim. Acta A Mol. Biomol. Spectrosc., 77, 1084 (2010); https://doi.org/10.1016/j.saa.2010.08.079.

14. V. Sumangala and N. Boja Poojarya, J. Chem. Pharm. Res., 4, 4979 (2012).

15. B.S. Jayashree, D. Anuratha and K.N. Venugopala, Asian J. Chem., 17, 2093 (2005).

16. H.A. El-Wahab, M.A. El-Fattah, N.A. El-Khalik and H.S. Nassar and M.M. Abdelall, Progr. Org. Coatings, 77, 1506 (2014); https://doi.org/10.1016/j.porgcoat.2014.04.026.

17. S. Myers and A. Baker, Nat. Biotechnol., 19, 727 (2001); https://doi.org/10.1038/90765.

18. C.M. Song, S.J. Lim and J.C. Tong, Brief. Bioinform., 10, 579 (2009); https://doi.org/10.1093/bib/bbp023.

19. D. Sajan, Y. Erdogdu, R. Reshmy, Ö. Dereli, K.K. Thomas and I.H. Joe, Spectrochim. Acta A Mol. Biomol. Spectrosc., 82, 118 (2011); https://doi.org/10.1016/j.saa.2011.07.013. 